\title{
Erratum to: MiRNA profiling of whole trabecular bone: identification of osteoporosis-related changes in MiRNAs in human hip bones
}

Laura De-Ugarte', Guy Yoskovitz' ${ }^{1}$ Susana Balcells², Robert Güerri-Fernández ${ }^{1,3}$, Santos Martinez-Diaz Leonardo Mellibovsky ${ }^{1,3}$, Roser Urreizti ${ }^{2}$, Xavier Nogués ${ }^{1,3}$, Daniel Grinberg ${ }^{2}$, Natalia García-Giralt1* and Adolfo Díez-Pérez ${ }^{1,3}$

\section{Erratum}

Funding for the work carried out in this article [1] was supported by grant FIS PI10/01537 and the Red Temática de Investigación Cooperativa en Envejecimiento y Fragilidad (RETICEF RD12/0043/0022) (Carlos III Health Institute, Science and Innovation Ministry), and FEDER funds.

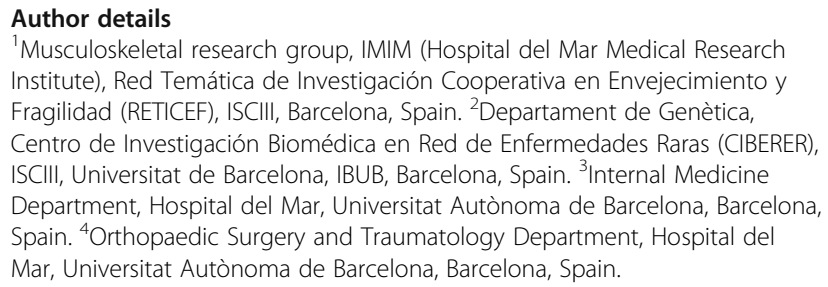

Received: 5 May 2017 Accepted: 9 May 2017

Published online: 23 May 2017

\section{Reference}

1. De-Ugarte L, Yoskovitz G, Balcells S, Güerri-Fernández R, Martinez-Diaz S,

Mellibovsky L, Urreizti R, Nogués X, Grinberg D, García-Giralt N, Díez-Pérez A.

MiRNA profiling of whole trabecular bone: identification of osteoporosis-related

changes in MiRNAs in human hip bones. BMC Medical Genomics. 2015;8:75.

doi:10.1186/s12920-015-0149-2.

\footnotetext{
* Correspondence: ngarcia@imim.es

${ }^{1}$ Musculoskeletal research group, IMIM (Hospital del Mar Medical Research Institute), Red Temática de Investigación Cooperativa en Envejecimiento y Fragilidad (RETICEF), ISCIII, Barcelona, Spain

Full list of author information is available at the end of the article
} 